\title{
IN VITRO ANTIMICROBIAL ACTIVITY AND MOLECULAR CHARACTERIZATION OF BACILLUS AMYLOLIQUEFACIENS ISOLATED FROM SIMILIPAL BIOSPHERE RESERVE, ODISHA, INDIA
}

\author{
IPSITA DAS ${ }^{1}$, MRUNMAYA KU PANDA ${ }^{1}$, CHANDI C.RATH ${ }^{2 *}$ \\ ${ }^{1}$ Department of Botany, Microbial Biotechnology Laboratory, North Orissa University, Baripada, Odisha, India. ${ }^{2}$ Department of Life \\ Sciences, Rama Devi Women's University, Bhubaneswar, Odisha, India.*Email: chandicharanrath@yahoo.com
}

Received: 27 August 2018, Revised and Accepted: 20 December 2018

\section{ABSTRACT}

Objective: The purpose of our study was to isolate and identify the bacteriocinogenic strain exhibiting broad range antimicrobial activity and to analyze the effect of different culturing conditions on the production of an antimicrobial metabolites isolated from the soil of Simlipal Biosphere Reserve, India.

Methods: In the current study, bacterial strains were screened for antimicrobial activity from soil samples of five different regions. The effect of varying culture conditions such as $\mathrm{pH}$, incubation period, and temperature along with carbon and nitrogen sources with and without certain salts was studied. The characterization of the potent strain was studied by morphological, biochemical, and 16S rRNA genetic sequencing. A phylogenetic affiliation of the strain was studied.

Results: A total of 31 out of 245 strains isolated from soil were screened on the basis of antimicrobial results against the test pathogens. On the basis of bacteriocin-like inhibition studies method, one potential isolate that exhibited the highest inhibition against all the pathogens was selected. The optimization of highest antimicrobial metabolite production by the isolate with the influence of physical parameters was found as the incubation period of 3 days with $37^{\circ} \mathrm{C}$ temperature at $\mathrm{pH} 8$ and for the chemical parameters dextrose was showed the most effective carbon sources when implemented with salts and yeast extract as the best sources of nitrogen with salts. The crude metabolite showed an absorbance peak value of 1.234 with optimum $\lambda$-max at $214 \mathrm{~nm}$. The potent isolate showed maximum identity with Bacillus amyloliquefaciens (99\% similarity) with highest query coverage on basic local alignment search tool search analysis of the $16 \mathrm{~S}$ rDNA sequence. Phylogenetic analysis revealed close affiliation of the isolate with B. amyloliquefaciens (KC494392.1) having antimicrobial activity.

Conclusion: The findings revealed that the incubation period, temperature, $\mathrm{pH}$, and the culture medium have a direct influence on the production of metabolites. These parameters can be modified for the improvement of the fermentation process.

Keywords: Bacillus amyloliquefaciens, Secondary metabolites, Antimicrobial activity, 16S rDNA sequencing, Phylogenetic study.

(C) 2019 The Authors. Published by Innovare Academic Sciences Pvt Ltd. This is an open access article under the CC BY license (http://creativecommons. org/licenses/by/4. 0/) DOI: http://dx.doi.org/10.22159/ajpcr.2019.v12i3.29319

\section{INTRODUCTION}

Rapidly rising strains of bacteria resistant to most advanced antibiotics have been an important public health concern. In response to the critical need for new drugs, for treatment of various infections and infectious diseases of humans and animals very few new antibiotics are being developed. There is a dire need to produce a remarkable range of antibiotics to solve the growing health problems in response to microbial resistance by the pharmaceutical industry [1]. Microbes are seen as a potential source for therapeutic uses with unlimited novel chemical structures [2], and they have the potentiality to grow in unique and extreme habitats, with the capability to produce unique and unusual metabolites. Many of these metabolites are believed to have certain chemicals to defend the microbes that compete for their survival [3]. Although a myriad of compounds with antimicrobial activity had been reported from various microorganisms over the decades, a few of them have determined to be clinically beneficial [4]. Till now, only $1 \%$ of the microorganisms had been studied while the advances in culturing techniques for microbes and extraction of their genes from various habitats have given scope for accessing an untapped reservoir of genetical and Metabolical diversity [5]. A large part of earth's surface is covered with soil. A large part of earth's surface is covered with soil.. It is the natural habitat for all organisms and is the center of important ecological processes. It is a major reservoir of microbial diversity due to its extreme complexity, a result of multiple interacting parameters such as shape, size, texture, structure, porosity, $\mathrm{pH}$, climatic variations, and biotic activity.
Bacteria are adaptive to diverse soil environments, and they produce secondary metabolites due to ecological stress. These secondary metabolites are invoked as special chemotherapeutic agents for lethal or inhibitory effects on other microbes in therapeutic concentrations with little or no toxic effect [6-7]. The temporal nature of secondary metabolite formation is genetic, but its expression can be influenced by manipulating different environmental parameters. The synthesis of antimicrobials is sought on by adding an inducer or by a decreasing the growth rate or by exhausting a nutrient [8].

The production of the antimicrobial metabolite depends on the basal medium required for their optimum growth, various concentrations of different nutrients in the medium, temperature, and $\mathrm{pH}$ [9]. Carbon and nitrogen are the important nutrients required for bacterial growth and enhancing the antimicrobial metabolite production. Continuous studies on the effect of the carbon and nitrogen sources for improved production of antimicrobial metabolites have been the subject by various industry and research groups for synthesis of newer drugs [10].

Thus, the objective of the study was to isolate a Bacillus spp. having antimicrobial activity from the soils of Simlipal Biosphere Reserve and to explore the influence of the physical and chemical conditions on the culture medium on biosynthesis of bioactive molecules. 


\section{METHODS}

\section{Chemicals}

The chemicals and media used in the current study were procured from HiMedia, Mumbai and Sigma-Aldrich, USA.

\section{Bacterial strains and growth conditions}

All the test pathogens (Escherichia coli, Enteropathogenic E. coli, Bacillus sp., Shigella dysentriae, Staphylococcus aureus, Vibrio cholerae 0139, and V. cholerea (Inaba) and four Candida species Candida albicans, Candida tropicalis, Candida parasilopsis, and Candida glabarata) were procured from the Microbial Type Culture Collection (MTCC), Institute of Microbial Technology (IMTECH), Chandigarh, India used in the current study. All bacteria were cultured in nutrient broth (NB) at $37^{\circ} \mathrm{C}$ for $16-18 \mathrm{~h}$

Sample collection and bacteriological analysis for source organism Composite soil samples were collected randomly from each plot collected from different sites of Similipal Biosphere Reserve, India, according to the method of Baruah and Barthakur, [11]. $1 \mathrm{~g}$ of soil was mixed with $9 \mathrm{ml}$ of autoclaved distilled water, homogenized using a vortex mixture and serially diluted with autoclaved water. Subsequently, $100 \mu \mathrm{l}$ of each dilution was spread onto Nutrient Agar (NA) agar plate (Hi-media), and the plates were incubated at $37^{\circ} \mathrm{C}$ for $24 \mathrm{~h}$. Well-isolated colonies were inoculated into fresh nutrient broth for stock preparation. Individual bacterial isolates were sub-cultured on NA medium to obtain pure culture and preserved at $4^{\circ} \mathrm{C}$ for further characterization. It was one of the isolates obtained by culturable method following dilution plate technique on NA medium. Further, the isolates were identified. The isolate was identified by series of morphological and biochemical characteristics up to generic level using Bergey's Manual of Determinative Bacteriology. Species confirmation of the isolate was carried out by $16 \mathrm{~S}$ rDNA sequence analysis.

\section{Determination of antimicrobial activity}

The bacterium was cultured in NB medium and incubated at $37^{\circ} \mathrm{C}$, for $24 \mathrm{~h}$. Preliminary antimicrobial activity was examined by spot inoculation and by disk diffusion method (Bauer et al.,) [12] against S. aureus Bacillus subtilis, Shigella dysentriae, V. cholerae (Inaba), C. albicans, and E. coli. All the test pathogens used in the study were procured from the MTCC, IMTECH Chandigarh, India.

\section{Secondary screening by bacteriocin-like inhibition studies (BLIS)} assay

The isolate showed positive antimicrobial activity both by disc and spot inoculation methods and was again subjected to secondary screening by BLIS assay. An overnight culture of the isolates was taken, and BLIS activity was done by the diametric-streak technique of Mayr-Harting et al., [13]. The test isolate was lawn cultured (1 inch) at the center of the NA plate by the help of a sterile cotton swab and incubated at $37^{\circ} \mathrm{C}$, for $24 \mathrm{~h}$. After the incubation period, the bacterial mass was swept out from the plate aseptically, and the plate was exposed to chloroform vapour for $40 \mathrm{~min}$ followed by exposure to ultraviolet (UV) radiation for $1 \mathrm{~h}$, to ensure the death of the cells. Then, freshly grown cultures of the test pathogens were streaked across the plates and incubated at $37^{\circ} \mathrm{C}$ for $24 \mathrm{~h}$. Plates were observed for growth on either side of the lawn, and no growth at the center represents potent antimicrobial activity by the isolate against the test pathogens.

\section{Statistical analysis}

The evaluation of results was done by taking mean data of two independent experiments with three replicates of different characterization studies. Correlation analysis was done to find out the linear association and to compare the factor level difference among the variables. All the analysis was carried out using SPSS software for windows release 19.0 version (SPSS Inc., IBM, New York, USA).

\section{Extraction of crude metabolites and antimicrobial study}

The isolate was cultured in the conditions that yield maximum metabolites. The filtrate which is cell-free $(500 \mathrm{ml})$ was neutralized with $1 \mathrm{~N} \mathrm{HCl}$, and resultant filtrate was extracted with an equal volume $(500 \mathrm{ml})$ of ethyl acetate thrice by vigorously shaking in a separating funnel. The ethyl acetate extracts were combined dried to obtain the crude extract. The antibacterial study was determined by the paper disk diffusion assay method [14].

\section{Metabolites determination by UV Analysis}

The $\lambda$-max in ethyl acetate of the crude metabolites was scanned using a UV spectrophotometer (Specord AU-2701,Systronics). For the presence of bioactive components at wavelength ranging from $190 \mathrm{~nm}$ to $550 \mathrm{~nm}$, and peak absorbance values were determined.

\section{Bioassay of the antimicrobial properties of the bioactive} compounds of the isolate

The selected isolate was incubated in a broth medium with required nutrients and was incubated at the rotary shaker at $120 \mathrm{rpm}$, and the compounds present in the broth was extracted by adapting liquid extraction method using ethyl acetate. The solvent portion was collected and concentrated by evaporation. The extract was then tested for the antimicrobial assay by agar well diffusion method, and the result was recorded by measuring the zone of inhibition produced.

\section{PCR amplification and 16Sr DNA sequencing}

Sequencing of $16 \mathrm{~S}$ rDNA of the isolate and amplification of the target gene was done using Big Dye Chemistry and performed as per the manufacturer's protocols (Applied Biosystems, USA). Universal bacterial primer 1492R (5'- TAC GGY TAC CTT GTT ACG ACT T-3') and the domain bacteria-specific primer 27F (5'- AGA GTT TGA TCM TGG CTC AG-3') were used for $16 \mathrm{~S}$ rDNA amplification. The PCR product was purified using QIA quick PCR purification kit (Qiagen). Purified 16S rDNA was sequenced partially using ABI PRISM big dye terminator cycle sequence reading reaction kit (Applied Biosystems) under the following conditions: Initial denaturation at $94^{\circ} \mathrm{C}$ for $5 \mathrm{~min} ; 30$ cycles of denaturation at $94^{\circ}$ for $45 \mathrm{~s}$, annealing at $48^{\circ} \mathrm{C}$ for $45 \mathrm{~s}$, extension at $72^{\circ} \mathrm{C}$ for $90 \mathrm{~s}$, and a final extension at $72^{\circ} \mathrm{C}$ for $5 \mathrm{~min}$. The purified sequencing reaction mixtures were electrophoresed using an Applied Biosystems model 310 automatic DNA sequencer (Perkin Elmer, Massachusetts USA). The sequence was annotated and submitted to GenBank.

\section{Homology search and phylogenetic analysis}

The 16S rDNA sequence of the isolate was been compared with the nonredundant databases in all GenBank + EMBL + DDBJ + PDB sequences (but no EST, STS, GSS, environmental samples or phase 0,1 , or 2 HTGS sequences) using the program Basic Local Alignment Search Tool(N) by selecting the optimization parameter to highly similar sequences (Megablast). The phylogenetic study was conducted by considering $16 \mathrm{~S}$ rDNA sequences of 20 bacterial isolates with antibacterial properties. The tree was generated by the neighbour joining method using MEGA 6.0 [15].

\section{RESULTS AND DISCUSSION}

\section{Isolation and identification of strain}

It is of interest to isolate the in vitro antagonistic potential of natural isolate against several pathogenic microorganisms. This study revealed the presence of a thermostable and barostable antimicrobial metabolite in the isolated bacterial strain. In our study, soil samples collected from selected sites of Simlipal Biosphere Reserve, Odisha, India, were screened for bacteria with antimicrobial activity against test pathogens. The bacterial strains that showed antagonistic activity on spread plate were isolated and tested by Petri plate assay. The strain (B5) exhibited good antimicrobial activity against selected Gram-positive, Gramnegative, and Candida strains. The Gram staining of the strain revealed it as Gram-positive, aerobic, motile, and rod-shaped as shown in Fig. 1 and spores were found in the later period, which was mid-born and Elliptical.

The morphological analysis of strain B5 showed the colony as milky white, opaque with smooth, and moist surface on NA plates adhering the medium tightly. Its colony surface becomes hilly and wrinkled in a later period, and its border gets transformed into a smooth white 
biofilm layer when cultured in liquid medium. The morphology of the strain was pinkish on HiCrome Bacillus Agar (Fig. 2). These studies suggested that strain B5 was Bacillus sp. and based on 16S rRNA gene sequence analysis, strain B5 was most likely Bacillus amyloliquefaciens.

The biochemical and physiological analysis of the strain showed the similarity of percentage identity with $B$. subtilis, which estimates the close proximity of the strain corresponding to the taxon relative to all other microorganisms. For further confirmation of the strain, 16S rDNA sequencing was done. The sequencing of the strain showed the maximum identity value of $99 \%$ with query coverage $99 \%$ and maximum score of 2667 with B. amyloliquefaciens (Fig. 3).

The phylogenetic analysis was conducted in MEGA6 [15], and the neighbour joining method was used to infer the evolutionary history [16]. The maximum composite likelihood method was followed to compute the evolutionary distances [17]. The analysis involved 20 nucleotide sequences. The rate variation among sites was modeled with a gamma distribution (shape parameter $=0.2$ ). The selected isolate $B$. amyloliquefaciens* (KM384034.1) clustered with B. amyloliquefaciens (KC494392.1) supported by bootstrap 67. Therefore, the isolated strain was confirmed as B. amyloliquefaciens based on the results of the morphological, biochemical, and 16S rDNA sequence analysis along with the phylogenetical study.

\section{Antimicrobial activity}

A total of 245 isolates showing a zone of inhibition around them were selected from the soil samples by crowed plate techniques and were preliminarily screened by disk diffusion and spot inoculation method for antimicrobial activity against test pathogens. About 31 isolates showed a zone of inhibition in both the methods followed they were then subjected to the BLIS method. This potent isolate B5 was found to exhibit good activity against the entire pathogens. A clear zone in the center of the NA plates with pathogens on both sides as shown in Fig. 4 indicated the antimicrobial potential of the isolate.

We studied the effects on the antimicrobial metabolite production by the strain B5 isolated from the soils of Simlipal Biosphere Reserve,

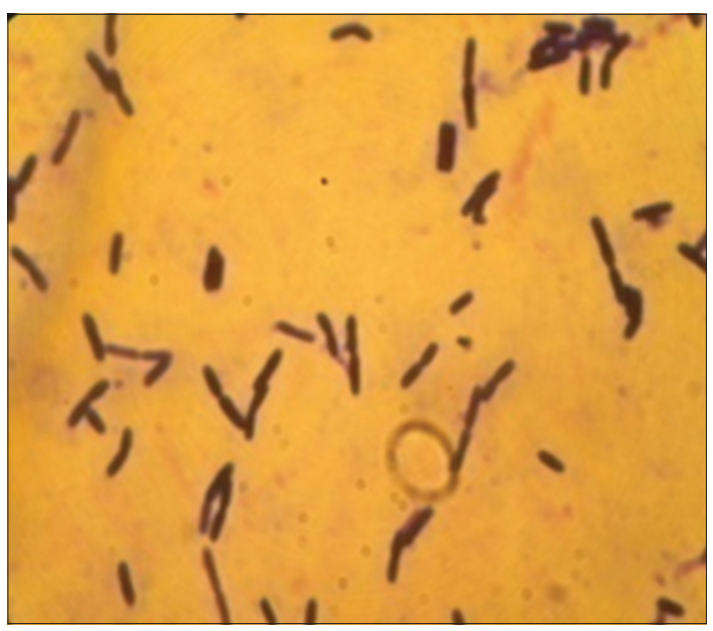

Fig. 1: Microscopic structure of B5
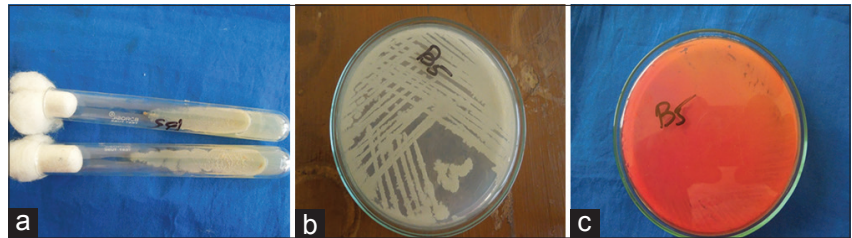

Fig. 2: (a) Isolate B5 on slant (b) Isolate on B5 NA plate (c) Isolate B5 on HiCrome Bacillus Agar medium
Odisha, India. Under different culturing conditions with a different array of species-specific features of varied physical and chemical factors were taken for developing efficient fermentation processes for the production of secondary metabolites in optimum media. Carbohydrate and nitrogen are essential for different structural and energy compounds in cells. Thus, various carbon and nitrogen sources along with certain salts as precursors were used in our study for determining the optimal medium for antimicrobial metabolite production by the strain B5. Different carbon and nitrogen sources at a concentration of $0.5 \mathrm{~g} / 100 \mathrm{ml}$ were added to the production media. A high degree of variation in the production of antimicrobial activity was found when different carbon and nitrogen sources were tested in the medium. The results showed that the most effective fermentative medium is with carbon sources as dextrose and the best source of nitrogen as yeast extract along with the addition of certain salts as precursors (Figs. 5 and 6) as compared the media without salts (Figs. 7 and 8).

Nutrients play a key role in the onset and intensification of secondary metabolites production in microorganisms. The results of our study showed a direct influence of incubation time, temperature, and the

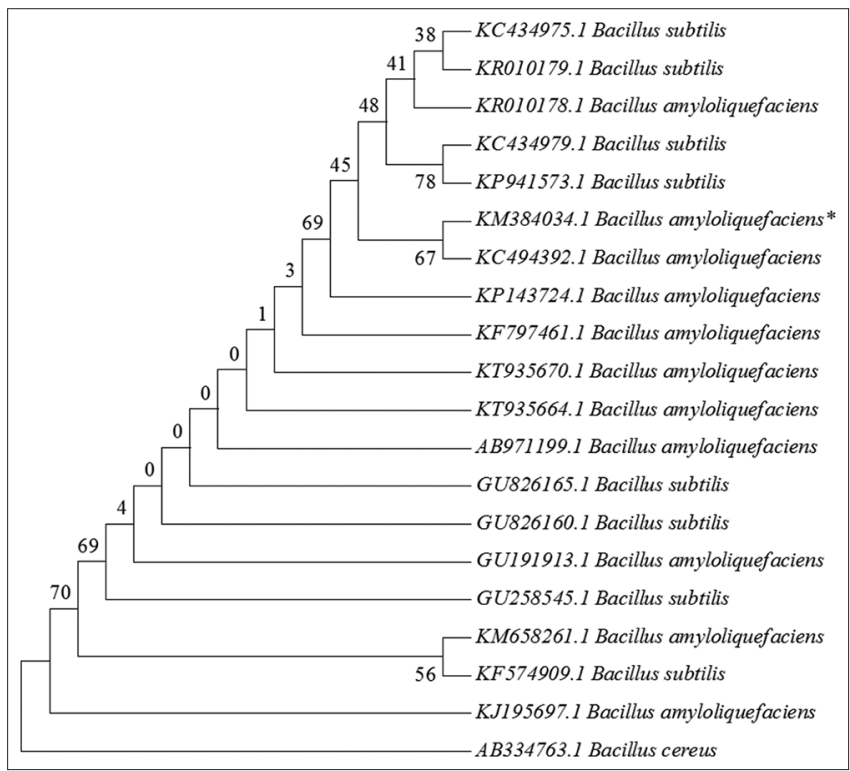

Fig.3: Phylogenetic analysis: Tree generated by neighbour joining method showed that the selected isolate clustered with Bacillus amyloliquefaciens (KC494392.1) supported by bootstrap 67

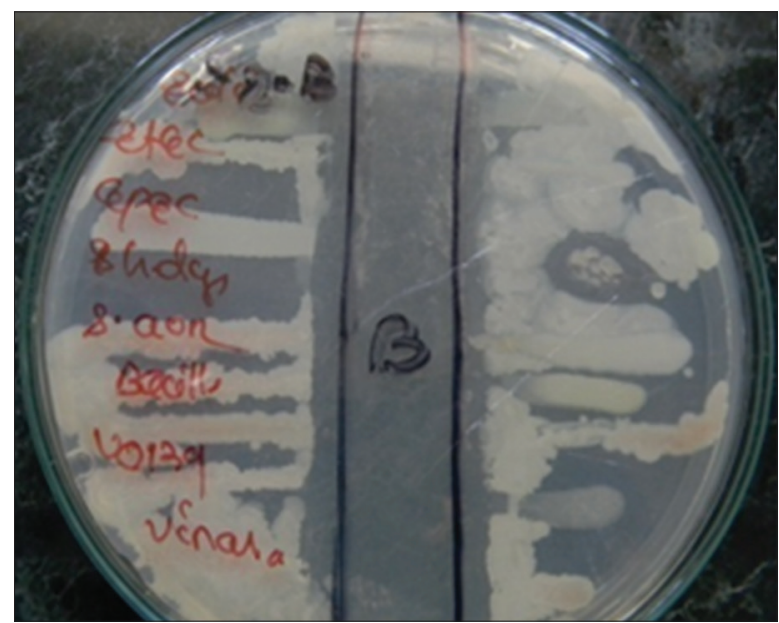

Fig. 4: Antagonistic activity of isolate B5 against different human pathogens by Bacteriocin Like Inhibition Studies method 
culturing medium on the production of secondary metabolites. These parameters can be modified for the optimizing and improvising the fermentation process for increasing the production of the compound of interest. Agar diffusion tests were done to study the antimicrobial activity of the culture filtrates under optimized conditions and for monitoring the time course for the production of the antimicrobial substances in batch culture, usually, in Bacillus, the time of antibiotic activity varies in between $24 \mathrm{~h}$ and $72 \mathrm{~h}$ of incubation. The time at which the maximum antibiotic activity occurs changes depending on the particular species of Bacillus as different species have different metabolic pathways [18]. The bacterial biomass and antibiotic activity of our isolate reached maximal levels in the medium containing dextrose with salts. The highest zone of inhibition was approximately $18 \mathrm{~mm}$. Studies that have investigated the effects of different concentrations of carbon and nitrogen sources on the activity of antibiotics show different results. The results usually depend on the particular type of microorganism used and its interaction with components of the medium, as differences in biosynthetic pathways can affect the activity of antibiotics. The change in $\mathrm{pH}$ affects many cellular processes as in the regulating the biosynthesis of secondary metabolites. The effect of $\mathrm{pH}$ on the antibiotic activity of our isolate was studied by adjusting the initial $\mathrm{pH}$ range (4.0-12.0) of the active medium. The optimal $\mathrm{pH}$ for maximal antibiotic activity from Bacillus sp. B5 was 8.0, and the zone of inhibition was $19 \mathrm{~mm}$ at this $\mathrm{pH}$ (Fig. 9).

The calibration for $\lambda$-max of the crude extract dissolved in ethyl acetate was studied. The scanning of the metabolite was done at a wavelength ranging from $190 \mathrm{~nm}$ to $550 \mathrm{~nm}$. The metabolites showed two peaks, but the optimum $\lambda$-max was shown at $214 \mathrm{~nm}$ with an absorbance value of 1.589 (Fig. 10).

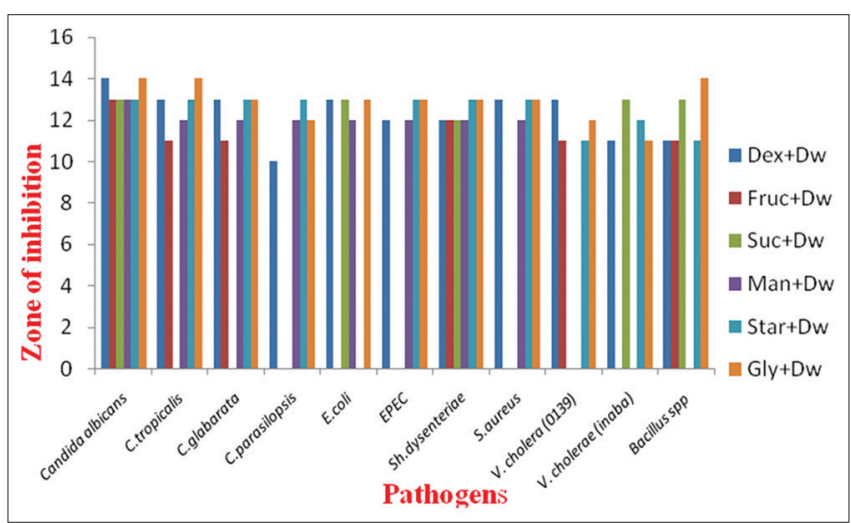

Fig. 5: Effect of different carbon sources $(0.5 \mathrm{~g} / 100 \mathrm{ml})$ on the activity of secondary metabolite of isolateB5 without salts

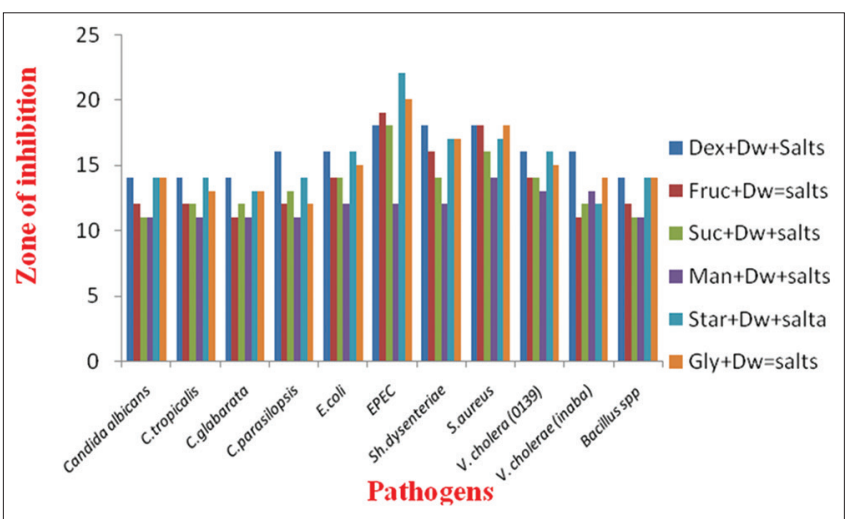

Fig. 6: Effect of different carbon sources $(0.5 \mathrm{~g} / 100 \mathrm{ml})$ on the activity of secondary metabolite of isolateB5 with salts
B. amyloliquefaciens is a species of the genus Bacillus was discovered in soil 1943 [19]. The genomics comparison of B. amyloliquefaciens reveals it to be closely related to $B$. subtilis with the similarity of $50 \%$ genes in the whole genome [20] and also as a synthesizer of several CLPs, such as iturins. [21]. The crude metabolites produced by the isolate B5 showed strong activity against a variety of Gram-positive bacteria, yeasts by agar diffusion test. The multifunctional process of antibiotics biosynthesis was demonstrated to be in control of limiting nutrients, which affects the metabolism. However in this present study addition of certain salts as percusers to the culture media increased the metabolite production and enhanced antimicrobial activity.

\section{DISCUSSION}

In our present study for antimicrobial metabolites producing microorganisms, an efficient antagonistic soil microorganism, B5, isolated from Simlipal Biosphere Reserve and identified as Bacillus amyloliquifiences. It exhibited remarkable antagonistic activity against different pathogenic test organisms. This species of Bacillus is an aerobic spore former found commonly in soil, groundwater, plants and animals during harvest or slaughter [22]. Studies based on the past decade analysis on antibiotic screening revealed most members of the genus Bacillus to have a contribution in the search for new antibiotics [23]. Different kinds of antibiotics that are found to be effective in suppressing the growth of target pathogens are being produced by many Bacillus spp. [24-25]. Similar results have also been reported by Pannapa and Pattra [26]. The antagonistic activity of the selected isolate B5 against several pathogens can be attributed due to the antibiotic effect. In this work, the composition of various carbon and nitrogen sources along with certain salts as precursors and environmental conditions such as $\mathrm{pH}$ and temperature influence

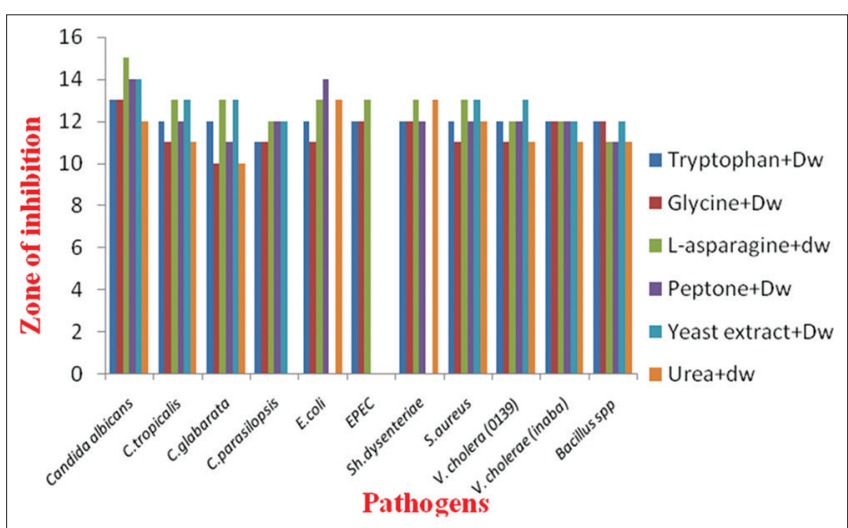

Fig. 7: Effect of different nitrogen sources $(0.5 \mathrm{~g} / 100 \mathrm{ml})$ on the activity of secondary metabolite of isolateB5 without salts

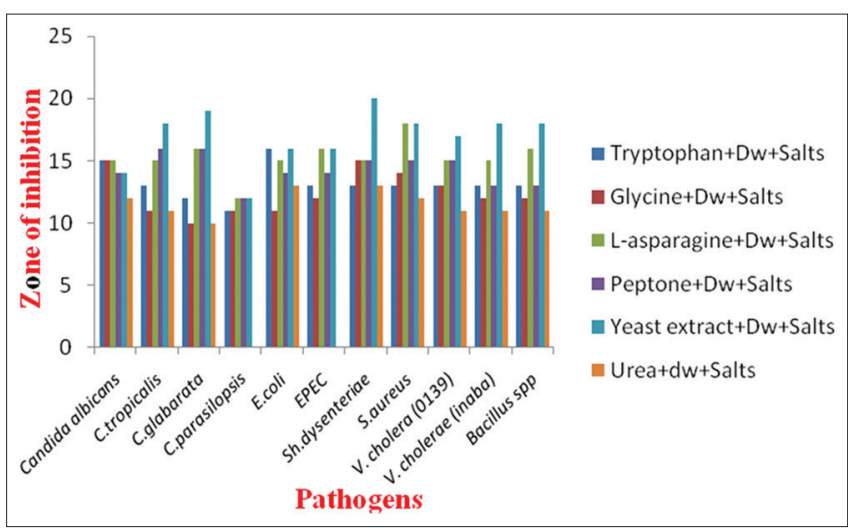

Fig. 8: Effect of different nitrogen sources $(0.5 \mathrm{~g} / 100 \mathrm{ml})$ on the activity of secondary metabolite of isolateB5 with salts 


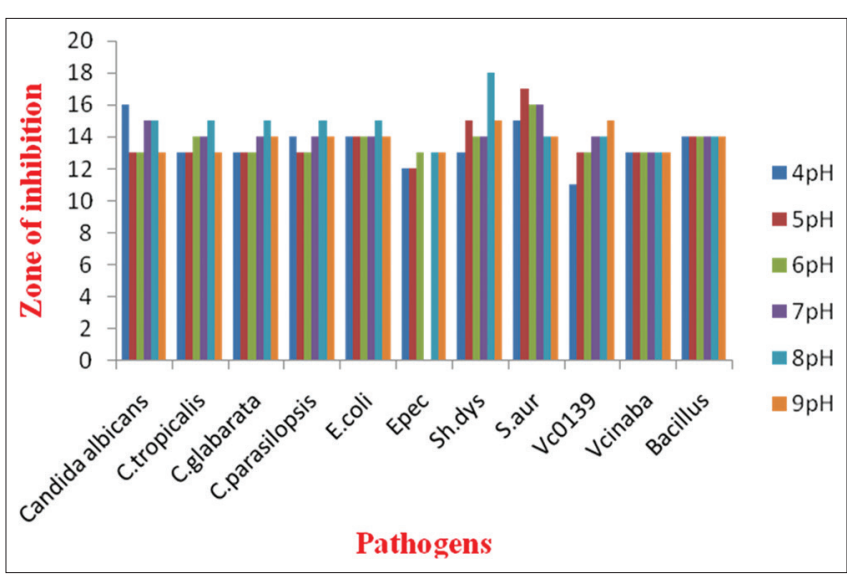

Fig. 9: Effect of pH on the activity of antimicrobial metabolite produced by isolates $\mathrm{B} 5$

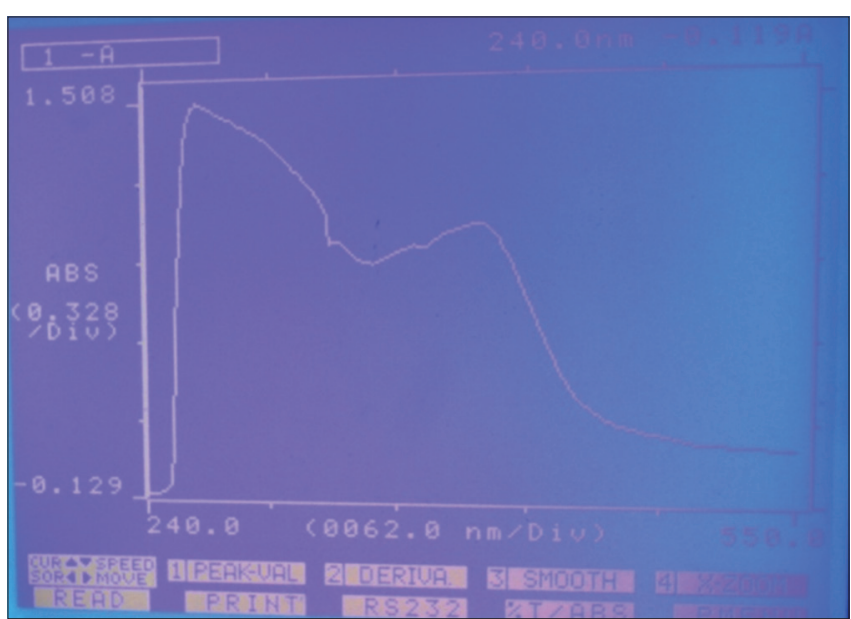

Fig. 10: Ultraviolet k-max in ethyl acetate of the crude metabolites produced by strain B5 (ABS: 1.234 at $214 \mathrm{~nm}$ )

isolate B5 for use in the production of antibiotic substances with antimicrobial activity. In the present study, dextrose $(0.5 \%)$ and yeast extract $(0.5 \%)$ along with certain salts used as a fermentative medium showed the potential activity of the antimicrobial metabolite produced by the isolate. The $\mathrm{pH}$ along with the incubation period is the critical factors for microbial growth and metabolic biosynthesis, which affect antibiotic production. The present study revealed 8.0 and $37^{\circ} \mathrm{C}$ as the optimum $\mathrm{pH}$ and temperature for production of antibiotic substances from isolate B5. The ethyl acetate extract of the isolate B5 significantly induced the inhibition of growth of test pathogenic microbes used in the study. In batch culture, the growth phase (trophophase) is followed by a production phase (idiophase) in the production of antibiotics [27]. The potent isolate (B5) seems to produce the antimicrobial substances in a fair amount in the culture broth. Under the conditions studied, the active substance is found to be accumulating late in the growth cycle, i.e., (in stationary phase), in liquid media reaching a maximum at $72 \mathrm{~h}$. Naclerio et al. [28] had reported the isolation of antibiotics of Bacillus spp. from the culture filtrates. The time required for fermentation for maximum yield of the antimicrobial metabolites production is different among different bacterial strains [9,29-32]. The antimicrobial spectrum of the active substances isolated from culture filtrate B5, determined by agar diffusion method, exhibited strong activity against a variety of Gram-positive bacteria, and yeasts, whereas less activity was detected against tested Gram-negative bacteria. El-Banna [33] had reported that the antimicrobial spectra of the active substances isolated from culture filtrates of Bacillus spp. such as B. cereus NB-4, B. cereus NB-5, and B. circulans NB-7 to have exhibited potent antifungal activity against filamentous fungi and yeasts. Carbon source plays an important role as a source of precursors and energies for the synthesis of biomass building blocks and secondary metabolite production $[34,35]$. The influences of medium components and environmental conditions are an initial and important step to improve the metabolite production of the genus Bacillus. Hence, the role of different carbon and nitrogen sources was studied for their influence and antibiotic production by this Bacillus strain. The results indicated that the production of the antimicrobial compound was maximum in the medium containing dextrose as the carbon source with salts. El-Banna [36] reported that glycerol and fructose were the best carbon sources for antimicrobial substances production. In our study on B5, lactose, maltose, sucrose, fructose, starch, glucose, and galactose showed less effect on antibiotic production. Several examples of secondary metabolites are reported to be suppressed by the presence of the carbon source. Glucose and ribose as carbon sources have been reported to interfere with the synthesis of secondary metabolites [37]. The antimicrobial activity of strain B5 was greatly influenced by nitrogen sources. Vahidi et al. [38] reported a high level of antifungal activity of Mycena leptocephala when yeast extract was used as a nitrogen source and lower antifungal activity when $\mathrm{NH} 4 \mathrm{Cl}$ and $\mathrm{NaNO}_{3}$ were used as nitrogen sources. The antimicrobial metabolite synthesis is often repressed by nutrients that favours rapid cellular growth, such as glucose (catabolite repression) and ammonium ions (nitrogen repression). However, when these nutrients level is low, the cellular growth rate is slowed, and the synthesis is decompressed [39]. The antimicrobial substance produced from any Bacillus species is believed to have the potency of an antimicrobial agent [40]. The strain B5 is found to be potent and effective against different test-organisms studied in vitro. Further, research is required in determining additional characteristics regarding purification, characterization, and identification of the active antimicrobial compound for it to become a good potent in pharmaceutical and biotechnological approaches.

\section{CONCLUSION}

Development of multiple drug resistance among pathogens is of global concern today. There is a constant pressure mounting among the researchers and academicians for the search of new antimicrobial compounds from microorganisms as well as from medicinal and aromatic plants. Although it is a preliminary endeavor, here we report the bacterial isolates of selected soil samples collected from soil samples of Simlipal Biosphere Reserve, producing antimicrobial compounds through both primary and secondary methods. Further, characterization would lead an alternate for development/discovery of newer antimicrobials and studies such as this are a prerequisite for tapping the biotechnological potential of these microorganisms.

\section{AUTHORS' CONTRIBUTIONS}

The first author performed the procedure, data collection, and analysis, manuscript preparation. The second author contributed toward statistical and phylogenetical analysis, and the last author contributed in study design and concept development. All the authors discussed and contributed to the final manuscript.

\section{CONFLICTS OF INTEREST}

We declare that we have no conflicts of interest.

\section{FINANCIAL SUPPORT}

This work was supported by MoEF, Government of India

\section{REFERENCES}

1. Luzhetskyy A, Pelzer S, Bechthold A. The future of natural products as a source of new antibiotics. Curr Opin Investig Drugs 2007;8:608-13.

2. Bĕhal V. Bioactive products from streptomyces. Adv Appl Microbiol 2000;47:113-56

3. Gallo M, Amonette R, Lauber C, Sinsabaugh RL, Zak DR. Microbial community structure and oxidative enzyme activity in nitrogenamended north temperate forest soils. Microb Ecol 2004;48:218-29.

4. Thomashow LS, Bonsali RF, David M. Detection of antibiotics 
produced by soil and rhizosphere microbes in situ. In: Karlovsky P, editor. Secondary Metabolites in Soil Ecology. Berlin Heidelberg: Springer; 2008.

5. Sánchez S. Microbial diversity-the bright and promising future of microbial manufacturing. Curr Opin Microbiol 2005;8:229-33.

6. Fravel DR. The role of antibiosis in biocontrol of plant diseases. Annu Rev Phytopathol 1988;26:75-91.

7. Thomsow LS, Bonsali RF, Weller DM. Antibiotic production by soil and rhizosphere microbes' in-situ. Man Environ Microbiol 1997:493-99.

8. Bibb MJ. Regulation of secondary metabolism in streptomycetes. Curr Opin Microbiol 2005;8:208-15.

9. Leifert C, Li H, Chidburee S, Hampson S, Workman S, Sigee D, et al. Antibiotic production and biocontrol activity by Bacillus subtilis CL27 and Bacillus pumilus CL45. J Appl Bacteriol 1995;78:97-108.

10. Sánchez S, Chávez A, Forero A, García-Huante Y, Romero A, Sánchez $\mathrm{M}$, et al. Carbon source regulation of antibiotic production. J Antibiot (Tokyo) 2010;63:442-59.

11. Baruah TC, Barthakur HP. Physico-chemical methods of soil analysis. In: Baruah TC, Barthakur HP, editors. A Text Book of Soil Analysis. New Delhi: Vikash Publishing House, Pvt. Ltd.; 1988. p. 34-69.

12. Bauer AW, Kirby WM, Sherris JC, Turck M. Antibiotic susceptibility testing by a standardized single disk method. Am J Clin Pathol 1966;45:493-6.

13. Mayr-Harting A, Hedges AJ, Berkeley RC. Methods for studying bacteriocins. Methods Microbiol 1972;7:315-422.

14. Lippert H, Brinkmeyer R, Mulhaupt T, Iken K. Antimicrobial activity in sub marine invertebrates. Polar Boil 2003;26:591-600.

15. Tamura K, Stecher G, Peterson D, Filipski A, Kumar S. MEGA6: Molecular evolutionary genetics analysis version 6.0. Mol Biol Evol 2013;30:2725-9.

16. Saitou N, Nei M. The neighbour-joining method: A new method for reconstructing phylogenetic trees. Mol Biol Evol 1987;4:406-25.

17. Felsenstein J. Confidence limits on phylogenies: An approach using the bootstrap. Evolution 1985;39:783-91.

18. Tamura K, Nei M, Kumar S. Prospects for inferring very large phylogenies by using the neighbour-joining method. Proc Natl Acad Sci U S A 2004;101:11030-5.

19. Janisiewicz W, Roitman J. Biological control of blue mold and gray mold on apple and pear with Pseudomonas cepacia. Phytopathology 1988;78:1697-700

20. Rooney AP, Price NP, Ehrhardt C, Swezey JL, Bannan JD. Phylogeny and molecular taxonomy of the Bacillus subtilis species complex and description of Bacillus subtilis subsp. In aquosorum subsp. Nov. Int J Syst Evol Microbial 2009;59:2429-36.

21. Fukumoto J. Studies on the production of bacterial amylase. I. Isolation of bacteria secreting potent amylases and their distribution. J Agric Chem Soci Jpn 1943;19:487-503.

22. Kaur S, Kaur J, Pankaj PP. Isolation and characterization of antibiotic producing microorganisms from soil samples of certain area of Punjab region of India. Int J Pharm Clin Res 2014;6:312-5.
23. Arguelles-Arias A, Ongena M, Halimi B, Lara Y, Brans A, Joris B, et al. Bacillus amyloliquefaciens GA1 as a source of potent antibiotics and other secondary metabolites for biocontrol of plant pathogens. Microb Cell Fact 2009;8:63.

24. Naclerio G, Ricca E, Sacco M, De Felice M. Antimicrobial activity of a newly identified bacteriocin of Bacillus cereus. Appl Environ Microbiol 1993;59:4313-6.

25. Tsuge K, Ano T, Shoda M. Isolation of a gene essential for biosynthesis of the lipopeptide antibiotics plipastatin B1 and surfactin in Bacillus subtilis YB8. Arch Microbiol 1996;165:243-51.

26. Pannapa P, Pattra S. Antimicrobial and enzyme activity produced by Bacillus spp. Isolated from soil. Int J Pharm Pharm Sci 2017;9:205-10.

27. Milner J, Raffel S, Lethbridge B, Handelsman J. Culture conditions that influence accumulation of zwittermicin A by Bacillus cereus UW 85. Appl Microbiol Biothechnol 1995;43:685-91.

28. Martin JF, Demain AL. Control of antibiotic biosynthesis. Microbiol Rev 1980;44:230-51

29. Meyers E, Brown W, Principe P, Rathnum M, Parker WE. A new peptide antibiotic. I. Fermentation, isolation, and preliminary characterization. J Antibiot 1973;26:444-8.

30. Jia Z, Zhang X, Cao X. Effects of carbon sources on fungal morphology and lovastatin biosynthesis by submerged cultivation of Aspergillus terreus. Asia Pac J Chem Eng 2009;4:672-77.

31. Zheng G, Slavik MF. Isolation, partial purification and characterization of a bacteriocin produced by a newly isolated Bacillus subtilis strain. Lett Appl Microbiol 1999;28:363-7.

32. Moyne AL, Shelby R, Cleveland TE, Tuzun S. Bacillomycin D: An iturin with antifungal activity against Aspergillus flavus. J Appl Microbiol 2001;90:622-9.

33. El-Banna N. Antimicrobial substances producing of the air flora. Arab Gulf J Sci Res 2003;21:134-9.

34. Wang YH, Li YP, Zhang Q, Zhang X. Enhanced antibiotic activity of Xenorhabdus nematophila by medium optimization. Bioresour Technol 2008;99:1708-15.

35. Lancini G, Parenti F. Antibiotics. New York, Heidelberg, Berlin: Springer-Verlag; 1982. p. 220-41.

36. El-Banna N. Effect of carbon source on the antimicrobial activity of the air flora. World J Microbiol Biotechnol 2005;21:1451-4

37. Berkely CW, Logan NA, Shute LA, Capey AG. Identification of Bacillus species. Method Microbial 1984;16:291-328.

38. Claus D, Berkely CW. The genus Bacillus. In: Sneath PH, editor. Bergeys Manual of Systematic Bacteriology. Vol. 2. Baltimore: Wilkins; 1986. p. 1105-39.

39. Vahidi H, Kobarfard F, Namjoyan F. Effect of cultivation conditions on growth and antifungal activity of Mycena leptocephala. Afr J Biotechnol 2004;3:606-9.

40. Sharma G, Dang S, Gupta S, Gabrani R. Identification and molecular characterization of bacteria having antimicrobial and antibiofilm activity. Int J Pharm Pharm Sci 2016;8:111-4. 